\title{
Virus and peace: a concerned editorial
}

\author{
Daniel A. Lowy 1,2* $^{*}$ \\ 1 VALOR HUNGARIAE, Ltd., Budapest, Hungary \\ 2 Dama Research Center limited, Kowloon, Hong Kong \\ *Correspondence: lowy.daniel@valhu.hu \\ (Online first): $30 / 05 / 2020$
}

How to cite: Lowy, A.D.. "Virus and peace: a concerned editorial" DRC Sustainable Future 2020, 1(1): Editorial. DOI: 10.37281/ DRCSF/1.1.editorial

Our editorial's title is inspired by Russian author Leo Tolstoy's novel War and Peace, first published as a book in 1869 , having an extent of 1,225 pages. In our collective memory, the "age of peace" refers to historical times, preceding World War I, often praised by our great-grandparents as the epoch of unprecedented technical and social progress, flourishing economy, middle-class safety, establishment of institutional bases of modern society and cultural renewal. In mid-December 2019, we have engaged in launching a new scientific journal on sustainable future, a publication dedicated to sustainability research aimed to support the well-being of current and future generations, without exhausting the resources of humankind. On the very last day of 2019, a new form of pneumonia, initially of unknown cause was detected in Wuhan, the capital city of Hubei province, the ninth most populous city of China (Kruse, 2020). Outbreak of the epidemic was announced in China, and the virus spread out fast from the eastern part of Asia, hitting every continent, except for Antarctica (Walsh, 2020), well before the World Health Organization declared COVID-19 pandemic, on March 11, 2020 (WHO, 2020). Since then, human society, economy in general and industrial production as well as maintaining cultural beliefs and practices, along with preserving cultural heritage (Soini and Birkland, 2014), and even everyday life have become the less and less sustainable.

Given this context, the focus of our first issue has changed, offering a feature article on the effects on air pollution (TSP) prior and after traffic restrictions and curfew against COVID-19 spread, in Ecuador's three most populated cities. Environmental monitoring was performed next to high traffic roads in Quito, Guayaquil, and Cuenca. After the implementation of traffic restrictions, the most striking drop in suspended particulate contained by air was measured in Cuenca, where $96.5 \%$ decrease in PM2.5 was assessed, relative to the emission observed prior to road traffic ban (Dama Research, 2020).

Other papers of this issue pertain sustainable agriculture. Zsolt Sándor and his co-workers investigated the effects of various soil cultivation methods on selected microbial soil properties. Work was done at the Látókép Experimental Station University of Debrecen, in Hungary, and considered were loosening cultivation and conventional ploughing. The total number of bacteria, soil respiration, biomass carbon and nitrogen, net nitrification, and dehydrogenase activity were measured under irrigated and nonirrigated conditions. Results demonstrate that loosening cultivation method (strip tillage with loosening) exerts a more favorable effect on parameters of biological activity proceeding in the soil, as compared to a conventional ploughing system (Zsolt Sándor et al., 2020).

In a single-author research paper, Anita Jakab determined several chemical soils parameters of fruit plantations in Szatmár and Bereg counties of North-east Hungary. Several chemical parameters were examined, including ammonium lactate- soluble phosphorus and potassium content of soils of fruit plantations. The author observed nutrient deficiency caused by acidification of soils, obtained results contributing to sustainable soil and land use (Jakab, 2020).

Soil-related studies are reported for an area with very different climate conditions: sandy soil, low in nutrients and organic matter, with poor water holding capability and low cation exchange capacity, in arid Botswana. Increasing soil moisture retention properties of Botswana's Kalahari sand, enables significant improvements in the country's traditional farming sector and, by this, one can implement the "No Poverty" and "Zero Hunger" sustainable development goals. This study specifically focusses on the 
ability of biochar, derived from poultry litter, to enhance moisture retention of the Kalahari sand (Shomana, Botha, and Agachi, 2020).

Miniaturization of separation science makes it more affordable and environmentally friendlier, given that considerably reduced amounts of organic solvents are discharged to the surroundings. Typically, handling, managing, disposing, or recycling spent solvents incurs important costs. Therefore, decreasing organic solvents consumption is important toward accomplishing sustainability of laboratories designated for research, R\&D, or education. One of the best resolving liquid separation techniques, which can benefit from miniaturization is capillary electrophoresis (CE), where analytes are separated by their hydrodynamic volume to charge ratio. Efforts toward optimizing sample preparation enabled significant reduction of chemicals required for analysis and a decrease of overall sample processing times. As a result, CE has become a sustainable separation technique. Máté Szarka, a Hungarian expert in the field, proposes a custom made, inexpensive CE unit, which benefits of LED induced fluorescent (LedIF) imaging detection, and demonstrates the applicability of the device in generating reliable scientific data. Samples were chosen from biotherapeutics industry. Results disclosed in this paper can serve as a demonstration of technical capabilities of current and future CE technique, which can be implemented and merged with existing solutions in a sustainable manner (Szarka, 2020).

Environmentally important findings are disclosed by Adrian Patrut and his Romanian-U.S.A. team, consisting of experts from Babes-Bolyai University, Cluj and NOSAS Facility, Woods Hole Oceanographic Institution. Authors report on their pioneering work of dating live African baobabs (Adansonia digitata), considered iconic trees by locals. Therefore, such giant trees serve as landmarks of the areas. Also, baobabs constitute a reliable archive of climate change and millennial specimens serve as proxies for paleoclimate reconstructions in southern Africa. Radiocarbon mass spectrometry is a technique able to reconstitute the history of climate change in a region, where written documentation is limited or unavailable. Authors disclose their recent findings on the age and structure of large size baobabs located on the volcanic Comoro Islands in the Indian Ocean, in between mainland Africa and Madagascar. The island is part Mayotte, which belongs to France, as an overseas department, hence, it represents the farthermost eastern territory of the European Union (Patrut et al., 2020).

Sasmita Baral and Dhiraj Kumar Nanda from the School of Biological Sciences, AIPH University, Odisha, India, scrutinize literature data on milk and its composition, methodology of quality assurance throughout its processing and preservation. Authors compare risks and benefits of consuming raw (unpackaged) and pasteurized (packaged) milk. This review is of wide academic and public interest, as it addresses issues related to the quality and safety of raw and pasteurized milk consumed by humans. Evaluation of risks and benefits simultaneously, yields many pros and cons of consuming raw and pasteurized milk, nevertheless, pasteurized milk appears to be more appropriate for consumption as compared to the lower quality raw milk. For manufacturing high quality pasteurized milk, one should implement good hygienic practices, proper pasteurization process, and pre and post pasteurization preservation, as well (Baral and Nanda, 2020).

Another exciting study pertains the butterfly effect applied to specific topics of this journal. Small events of durations as short as a quarter of a second may affect the overall outcome of a global trend. Authors propose a change of perspective, in that one should confer much greater importance to small causes. Butterfly-effect is addressed, based on a real, but anonymous data asset, where each step is reproducible. The problem to be solved is, how one can classify personal time series in frame of similarity analysis. Sustainability can be redefined as a capability of forecasting system behavior. Random-like, notplanned incidents cannot be accepted as sustainable and realized plan values. The most common application of the sustainability approach taken in this paper is precision farming (Dávid et al., 2020).

Sustainable energy issues are addressed in a paper on magnesium-air reserve batteries, which can store energy indefinitely, releasing it on demand, in emergency situations. The main advantage of wateractivated batteries is that their electrolyte is supplied by the environment, where they get deployed. Therefore, only light weight electrodes and battery frames need to be transported, rather than carrying the significantly heavier aqueous electrolyte. While the specific energy of reserve batteries can be determined unambiguously, their energy density calculation needs a clear definition of the considered battery volume. The paper provides an overview of recent literature in the field and proposes a new modality of calculating specific energy and energy density of seawater-activated metal-air reserve batteries for prismatic and cylindrical geometries, respectively. One additional merit of this account is that recently, battery storage 
has become an effective way to increase share of renewables in photovoltaic energy systems utilized in farming. (Lowy and Matyas, 2020).

We proudly offer to the scientific community this first issue of our journal, which was peerreviewed, completed, edited, and published in an unprecedentedly difficult time of the modern era, the COVID-19 pandemic. The Editors are confident that launching this issue, created from December 2019 through April 2020, will provide hope that science cannot be defeated by any virus or disease. Scientific research remains sustainable.

\section{References}

Baral, S. and Kumar, D. "Risk and benefits of consuming raw (unpackaged) and pasteurized (packaged) milk." DRC Sustainable Future 2020, 1(1): 23-32, DOI: 10.37281/DRCSF/1.1.4

Dama Research (2020). Effect of transport measures and curfew against COVID-19 spread on air pollution (TSP) in Ecuador's three most populous cities. DRC Sustainable Future 2020, 1(1): 33-40. DOI: 10.37281/DRCSF/1.1.7

Dávid, R., Pitlik, L., Pitlik, M., Pitlik, M., Pitlik, L. "Sustainability from Philosophical and Mathematical Standpoint: Butterfly-Effects in Similarity Analyses of Time Series". DRC Sustainable Future 2020, 1(1), DOI: 10.37281/DRCSF/ 1.1.10

Jakab, A. "The ammonium lactate soluble potassium and phosphorus content of the soils of north-east Hungary region: a quantifying study. DRC Sustainable Future 2020, 1(1): 7-13. DOI: 10.37281/DRCSF/1.1.2

Kruse R.L. "Therapeutic strategies in an outbreak scenario to treat the novel coronavirus originating in Wuhan, China. F1000Research 2020, 9 (72). Web access: https://doi.org/10.12688/f1000research.22211.2

Lowy, D.A. and Matyas, B. "Sea Water Activated Magnesium-Air Reserve Batteries: Calculation of Specific Energy and Energy Density for Various Cell Geometries.” DRC Sustainable Future 2020, 1(1): 1-6. DOI: 10.37281/DRCSF/ 1.1.1

Patrut, A., Patrut, R.T., Rakosy, L., von Reden, K.F. “Age and architecture of the largest African Baobabs from Mayotte, France.” DRC Sustainable Future 2020, 1(1): 33-47. DOI: 10.37281/DRCSF/1.1.1

Sándor, Zs., Tállai, M., Kincses, I., László, Z., Kátai, J., Vágó, I. "Effect of various soil cultivation methods on some microbial soil properties". DRC Sustainable Future 2020, 1(1): 14-20. DOI: 10.37281/DRCSF/1.1.3

Shomana, T., Botha, D.E., Agachi, P.S. "Water retention properties of biochar derived from broiler poultry litter as applied to the Botswana's soil.” DRC Sustainable Future 2020, 1(1): 67-72. DOI: 10.37281/DRCSF/1.1.9

Soini, K. and Birkland, I. "Exploring the scientific discourse on cultural sustainability". Geoforum 2014, 51: $213-223$. doi:10.1016/j.geoforum.2013.12.001

Szarka, M. "Greening Capillary Electrophoresis, a promising sprout of Separation Science toward sustainability" DRC Sustainable Future 2020 1(1): 60-65. DOI: 10.37281/DRCSF/1.1.8

Walsh, B. Covid-19: The history of pandemics. BBC Future 2020, March 26, 2020. https://www.bbc.com/future/article/ 20200325-covid-19-the-history-of-pandemics (Accessed on March 27, 2020).

WHO (2020). WHO announces COVID-19 outbreak a pandemic. World Health Organization - Regional Office for Europe. http://www.euro.who.int/en/health-topics/health-emergencies/coronavirus-covid-19/news/news/2020/3/whoannounces-covid-19-outbreak-a-pandemic (Accessed on March 27, 2020). 